\title{
HISTÓRIA E PSICOLOGIA NA HERMENÊUTICA DA CULTURA DE DILTHEY
}

\author{
Sônia Maria da Silva Araújo*
}

\begin{abstract}
RESUMO
Este texto discorre sobre o trabalho desenvolvido por Wilhelm Dilthey no campo da cultura, para a compreensão do espírito. Limita-se a entender como Dilthey pensava alçar, por meio da arte principalmente da poesia e da literatura -, o espírito humano. A cultura, para Dilthey, é fonte privilegiada de tradução das reais condições psíquicas e históricas do homem no tempo; ela é um tecido de nexos finais, que possui uma estrutura. Esta estrutura conforma a construção imaginativa (Einbildungskraft) humana e por meio dela é possível entender o homem na sua mais profunda concretude. O texto está constituído de três partes. Na primeira, retomo as idéias basilares de Dilthey sobre a História, a Psicologia e a Filosofia. Na segunda, trato da questão da Poesia e da Literatura, destacando como estas manifestações do espírito são apreendidas por Dilthey. Na terceira, traço considerações particulares sobre sua hermenêutica.

Palavras-chave: Ciências do Espírito. Enigma da Vida. Cultura. Construção Imaginativa.
\end{abstract}

\begin{abstract}
This text is about a study carried out by Wilhelm Dilthey in the field of culture, aiming the understanding of the soul. Its scope is

\footnotetext{
* Doutora em Educação pela USP-SP e professora do Instituto de Ciências da Educação e do Programa de Pós-Graduação em Educação da Universidade Federal do Pará - UFPA. E-mail: somentesonia@hotmail.com
} 
to investigate how Dilthey sees the arts - mainly poety and literature - to reach the human soul. Culture, according to Dilthey, is a priviledged source of translation of the historical and psycological circumstances of mankind in time; it is a tissue of final that has one structure. This structure consists in the construction of the human imagery (Einbildungskraft); concept by means of which it is possible to understand the human being in its deepest concrete form. The text consists of three main parts. In the first one, review Dilthey's basic ideas about history, psychology and philosophy. In the second part, I discuss Poetry and Literature, underlining the way Dilthey approaches such manifestations of the soul. In the third part, I comment on my point of view of Dilthey's hermeneutics.

Keywords: Science of the Soul. Mystery of Life. Culture. Construction of de Imagery.

\section{Dilthey, a história, a filosofia e a psicológia descritiva}

Nascido em Biebrich, na Alemanha, Dilthey viveu de 1833 a 1911. Foi professor de história da Filosofia, em Berlim. Filho de um pastor calvinista estava, diz Eugênio Imaz, destinado a seguir a carreira do pai. Extremamente modesto, Dilthey sempre assinala em seus escritos, nos fala Eugênio, seu caráter provisório quando os anunciava como planos, projetos, materiais ou contribuições. Envolvido com questões teóricas de sua época, Dilthey dialogou intensivamente com grandes teóricos de Berlin, principalmente com os da Escola Histórica - Humboldt, Savigny, Grimm, Ritter e Ranke -, que, como ele, não aceitavam o idealismo hegeliano. Apesar de ter sido um crítico voraz do pensamento metafísico, para o qual dedicou extensas páginas de escritos críticos, esteve visivelmente "afinado" com as tendências teóricas de sua época, mas, mesmo assim, não poupou críticas ao positivismo. Ou seja, ainda que tenha se unido aos positivistas contra o pensamento metafísico, não concordava com o naturalismo imposto por ele às ciências

Educ. e Filos., Uberlândia, v. 22, n. 44, p. 159-184, jul./dez. 2008. 
humanas. Aliás, sua obra se desenvolve neste sentido: o de se objetar, veementemente, a esta forte disposição. Crítico cruel de Hegel e de Comte, disse que o idealismo estava morto, mas que o positivismo não era a solução. A História ${ }^{1}$ que defendia se contrapunha à de Hegel e se alinhava às de Windelband e Rickert, as quais se articulavam à filosofia da vida. Assim, seus estudos, históricos por princípio e natureza, advertiam para as circunstâncias hermenêutico-psicológicas que envolvem o homem e se afastam de qualquer apriorismo e empirismo historiográfico.

Para Dilthey as coisas e a própria vida deveriam se sobrepor ao espírito, e a história deveria se fundar na sistematização da cultura para alcançar a vida mesma. Neste sentido, concebe a história como condições de possibilidade de organização do mundo - o mundo da cultura. Este, por sua vez, estaria inscrito na estrutura e no conteúdo dos documentos, dos monumentos e nas obras literárias e artísticas. Para ele, o mundo da cultura nos envolve por todas as partes e constitui o cenário de nossa vida. Assim, o historiador e o sistemático se conjugam no sentido de fundamentar gnoseologicamente todo o saber elaborado pelo homem e garantir a reflexão sobre a realidade: a filosofia. Dizia, então, que a tarefa da filosofia consiste em compreender, revivendo com uma experiência íntima, a vida do espírito em sua evolução histórica.

Dilthey separa, enfaticamente, as ciências da natureza das ciências do espírito muito mais pelos conteúdos (que para ele são completamente diferentes) do que pelo método e objeto. As ciências do espírito, para ele, devem se pautar em feitos espirituais e estes são de outra natureza. Eles são dados integralmente aprendidos em toda a sua realidade e que funcionam como uma autognose, ou seja, como um conhecimento que conhece a realidade - como é o caso da literatura, da poesia e da arte. E, segundo Dilthey, essa

1 Para Dilthey (1949, p. 4-5) a escola histórica, predominantemente marcada pelo apriorismo hegeliano, não havia conseguido superar a questão das limitações internas dos fatos históricos, obscurecendo seu próprio desenvolvimento teórico e sua influência sobre a vida.

Educ. e Filos., Uberlândia, v. 22, n. 44, p. 159-184, jul./dez. 2008. 
autognose se converte em apreensão do psíquico-espiritual. Diz ele que autognose é o conhecimento das condições da consciência nas quais se efetua a elevação do espírito à sua autonomia mediante determinações de validez universal. Neste caso, as ciências do espírito antecedem, gnoseologicamente, as da natureza que são criações históricas. Os fundamentos desse conhecimento que conhece, Dilthey vai buscar na psicologia. Para ele, a psicologia permite compreender o homem como entidade histórica e não como uma substância; é neste sentido que ela se coloca em sua obra: como uma fundamentação das ciências do espírito, como uma sistemática composta de material histórico. Daí Dilthey conceber a psicologia como descritiva e analítica, e não como explicativa ou interpretativa.

Certo de que era preciso prover um método próprio para as ciências do espírito, Dilthey adentra na questão da teoria do conhecimento das ciências do espírito e diz que seus fins - captar o singular, o individual da realidade histórico-social, conhecer as uniformidades que operam em sua formação, estabelecer os fins e regras para sua futura criação - podem ser alcançados unicamente por meio dos recursos do pensamento, por meio de análises e da abstração. Para ele, a diferença entre as ciências do espírito e as ciências da natureza reside, fundamentalmente, nos conteúdos. Ele diz que:

Em ambas descobrimos leis e ambas coincidem em seus objetos, porém a diferença de conteúdos assegura sua distinção e ilumina algumas particularidades importantes de cada qual... Porém, apesar dessa diferença, as mesmas operações mentais são utilizadas e postas em jogo em ambas ciências: comparar, abstrair, diferenciar, enlaçar, julgar, se realizam as mesmas operações lógicas: indução, silogismo, raciocínio por analogia, subordinação ao geral, etc. Nas ciências naturais predomina a indução; nas ciências do espírito a comparação (DILTHEY, 1944, p.40).

Segundo Heidegger, Dilthey tinha como meta "elevar a vida" a uma compreensão filosófica e assegurar um fundamento

Educ. e Filos., Uberlândia, v. 22, n. 44, p. 159-184, jul./dez. 2008. 
hermenêutico ${ }^{2}$ a esta compreensão da "vida mesma". Mas, para que esta compreensão fosse alçada, Dilthey, a princípio, investe esforços na psicologia, em uma psicologia que ele chama de descritiva e analítica em oposição a uma psicologia explicativa. Depois, investe na hermenêutica que daria suporte metodológico e auto-aclararia as conexões dos modos mais elementares de viver e expor, em última instância, a evolução do espírito. Por esta via, emerge em Dilthey um novo objeto: o espírito do tempo. Pois, para ele:

Toda época oferece uma fisionomia determinada constituída por certos traços gerais aos quais não estão salvos os indivíduos por mais forte que seja sua personalidade, mas, pelo contrário, alcança neles sua expressão mais alta e se exterioriza na obra das grandes personalidades, nas diversas esferas da vida: religião, poesia, música, filosofia, direito, economia, etc. (DILTHEY, 1944, p. 21).

O espírito do tempo se dissemina em todas as manifestações culturais e exige do historiador que a elas recorra para conhecer plenamente a história de toda e qualquer época. ${ }^{3}$ Para Dilthey todas as criações culturais estão penetradas pelo espírito da época e participam da historicidade inerente ao ser espiritual e que para conhecer um indivíduo, para interpretar uma época ou uma criação cultural é preciso recorrer à história. A cultura, então, só pode ser indagada e examinada em consonância com o tempo em que foi elaborada. Ora, é essa relação entre o tempo e a cultura

2 No século XIX, Dilthey vinculou o termo "hermenêutica" à sua filosofia da "Compreensão vital": as formas da cultura, no curso da história, devem ser apreendidas através da experiência íntima de um sujeito; cada produção espiritual é somente o reflexo de uma cosmovisão (Weltanschauung) e toda filosofia é uma "filosofia da vida".

3 Concebe Dilthey que em cada momento do tempo - momento que pode abarcar séculos - a situação da consciência, a densidade da experiência da vida, os avatares da história, fazem com que o homem produza sistemas, estilos artísticos e revelações religiosas. Este é o espetáculo da história e, também, a chave capaz de nos fazer estabelecer a conexão entre as ciências que se ocupam da arte, da filosofia e da religião, e compreender, nas entranhas da vida, as condições do conhecimento na consciência.

Educ. e Filos., Uberlândia, v. 22, n. 44, p. 159-184, jul./dez. 2008. 
que nos possibilita conhecer a realidade e entender a história. A vida espiritual se constitui, por assim dizer, na matéria prima da história, porque é ela, manifesta no direito, na religião, na arte e tantos outros conhecimentos, que regula a vida prática e traz à consciência as variações diversas do homem.

Ao identificar nexos no conjunto de uma produção cultural, em uma determinada época, por meio da sistematização, estaremos, segundo Dilthey, revelando o movimento do espírito e compreendendo o processo de plasticidade ao qual todos estamos sujeitos. Isto porque, para ele, enquanto seres históricos estabelecemos interconexões entre repertórios de épocas e que acabam por resultar em modos de viver e de pensar nunca puros ou originários. Para ele, o homem não se desprende de seu passado para começar tudo de novo sem prejuízo algum; ele é sempre parte do passado. Portanto, só é possível compreendê-lo se se recorrer ao passado. Mas a busca desse passado deve se processar por modos particulares de investigação, distintos daqueles manipulados pelas ciências da natureza. Ele diz:

A experiência do passado, plenamente assimilada, se incorpora e se fixa como um elemento plástico e influi sobre os atos do presente. Porém, além disso, ao homem se coloca viver em uma época determinada que é, em seu turno, sobras de outras épocas e que oferece uma paisagem cultural em mínima parte criado por ela e em máximo herdado de épocas pretéritas. A figura espiritual mutante de uma época imprime seu selo sobre o homem e lhe impõe todo um repertório de idéias, crenças, gestos, preferências, etc. Ao assimilar essa herança espiritual, não sem modificá-la, o homem conquista a altura cultural de seu tempo e desde ali se percebe a si mesmo como ser histórico (DILTHEY, 1944, p. 23).

Frente a esta visão, Dilthey, polemicamente, se coloca em oposição ao primado da razão, tão presente entre os racionalistas e empiristas de seu tempo. A razão, defende, não é igual em todos os homens e, portanto, é difícil encontrar regularidade no comportamento humano, como defendem Descartes e Hume.

Educ. e Filos., Uberlândia, v. 22, n. 44, p. 159-184, jul./dez. 2008. 
Estas idéias indicam, com especial clareza, o afastamento de Dilthey a qualquer tentativa de generalização. A história, para ele, é sempre uma história particular, capturada por situações singularmente próprias do tempo. Também revelam essas idéias uma oposição à razão pura de Kant. ${ }^{4}$ A razão histórica de Dilthey se contrapõe à premissa de que todos os homens, independente de tempo e espaço, têm uma base imutável (razão pura), uniforme, desarticulada das demais atividades psíquicas. A razão histórica é concebida como a plenitude de funções intelectivas, afetivas e volitivas relativas às épocas.

A história é para Dilthey, em síntese, um esforço sistemático que deve proporcionar um fundamento gnoseológico a todo saber histórico, seja ele: religioso, poético, literário ou científico. A história é, então, por assim dizer, o pensamento sobre o pensamento, a reflexão da reflexão. Todo este esforço, pensa Dilthey, ofereceria ao historiador condições de compreender a vida do espírito em sua mais extensa evolução histórica. Ao fazer isto, Dilthey articula história e estudo do homem, aproximando da primeira a psicologia e a antropologia. Neste caso, atribui a estas duas últimas a base sobre a qual descansa a filosofia.

A realidade empírica é então, por meio da cultura, recolocada pela história e Dilthey, à sua maneira, leva às últimas conseqüências a concepção de história dos pensadores da Escola Histórica, principalmente a de Ranke: a de dizer tão só como efetivamente têm ocorrido as coisas. Porém, Dilthey se propõe a avançar no processo historiográfico para além destes ao tentar examinar os motivos pelos quais os feitos culturais ocorrem; de procurar, por meio da psicologia e da antropologia, penetrar na alma humana e entender seus conflitos mais imediatos. Desta forma, Dilthey pensa elevar a

${ }^{4}$ Para Kant, o homem, enquanto sujeito do conhecimento, é um ser puramente intelectual. Em contraposição, Dilthey fala de um homem pleno, em relação constante com as suas condições de possibilidade; um homem histórico. As funções intelectuais não são um produto do indivíduo isolado, mas um processo de evolução do gênero humano. Pensando assim, Dilthey descarta os a priori da consciência pura de Kant - intuição, categorias e idéias.

Educ. e Filos., Uberlândia, v. 22, n. 44, p. 159-184, jul./dez. 2008 
história à consciência, pois defende que só ela (a consciência) nos adverte para a nossa relação com o mundo e fundamenta todo o conhecer.

Em verdade, Dilthey, ao colocar a cultura como instrumento privilegiado de compreensão da vida humana, tentando resgatála a partir de interconexões, concebe a razão como resultante das relações do homem no tempo. Esta idéia levada a cabo por Dilthey, o faz, inclusive, dizer que as próprias ciências naturais são produto histórico submetido à evolução. Mas, no caso das ciências do espírito, sua construção se coloca como necessariamente vinculada ao repertório cultural dos homens e para reconhecê-lo, ou melhor, revivê-lo, na sua plenitude, é preciso reconstituir a sua natureza por intermédio da psicologia. Mas, ressalta, não se trata de uma psicologia naturalista, pautada no modelo metodológico das ciências da natureza e carregada de positivismo. Trata-se, adverte, de uma psicologia descritiva ou analítica, capaz de retratar o homem na sua relação com o mundo, portanto, com a sua vida mesma.

Esta psicologia descritiva, para a qual Dilthey dedica inúmeras páginas de escritos, decorre da idéia de que o psíquico é dado imediatamente na consciência pelas condições históricas de possibilidade, determinadas pelo passado e pelo presente - a vida anímica. Para Dilthey, "a vida anímica constitui um complexo de disposições solidárias, que evoluem através do tempo e na qual o passado persiste e influi sobre toda experiência nova" (1944, p. 26-27). Ao descrever a consciência, registrando o caráter volúvel, alternado e mutante das vivências é possível, assegura Dilthey, descobrir plásticas formas estruturais, típicas e objetivas amalgamadas empiricamente nos homens ao longo do tempo. À psicologia cabe, então, descrever e analisar o complexo estrutural da vida anímica. ${ }^{5}$

Princípio da sensibilidade e do pensamento, que faz a distinção entre matéria inerte e corpo vivo, o ânima (sopro de vida) é o

5 A vida expressa no rosto, no olhar, nos gestos, na linguagem. Enfim, nos signos exteriores que revelam a interioridade dos homens.

Educ. e Filos., Uberlândia, v. 22, n. 44, p. 159-184, jul./dez. 2008. 
vínculo do homem à vida concreta. Ora, isto significa dizer que para descrever o homem, tal qual ele se apresenta, precisamos abstrair conceitos circunscritos às vivências do sujeito em estudo, e não nele mesmo. As vivências são a base, o material de análise; nela, e somente nela, é possível alçar as representações e as funções da vida na sua totalidade e que servem de fundamento ao conhecimento; em particular, ao das ciências do espírito. Estas representações e funções estão, na perspectiva de Dilthey, reapresentadas e entranhadas na cultura, no pensar discursivo que ela institui. Dilthey, em verdade, acreditava ser possível, por meio do pensar discursivo (objeto então da psicologia), adentrar no círculo empírico da consciência e (re)conhecer a realidade.

A realidade da qual trata Dilthey, não é a realidade do mundo exterior, mas a realidade volitiva, a manifestação da vontade (desejo e escolha). A vida anímica, neste caso, se coloca como necessária ao alcance desta vontade. É ela que, em última instância, permite a experiência íntima daqueles que pretendem se pôr em contato com a realidade e compreender as vivências de tipos humanos passados.

Psicologia e História estão profundamente articuladas em Dilthey. Para ele, a vida psíquica apresenta regulações, que são estabelecidas pelas condições históricas, e que só é possível descrevêla na medida em que se conhece a vida vivida. Isto só pode se processar se se tomar como análise produções que poderão ser comparadas entre si e no tempo. Para tal, defende Dilthey: os espíritos, objetos de conhecimento do homem, precisam ser representativos no contexto da produção cultural, como é o caso da poesia, da arte, da religião e da literatura.

Dilthey acreditava que a psicologia podia proporcionar o elo entre as ciências do espírito: a história, a teoria da literatura e da arte, a jurisprudência, a filologia, as ciências do Estado e da organização externa da sociedade, a política, a teologia. Para ele, até então, estaria sob o domínio da psicologia o conhecimento sobre o sentimento, a vontade, a dependência, a liberdade, o motivo, e que por isso ela revelaria a vida interior, porque só ela penetra na zona do sentimento e compreende as "experiências do coração" que movem a vontade. A psicologia, segundo ele, tem por tarefa:

Educ. e Filos., Uberlândia, v. 22, n. 44, p. 159-184, jul./dez. 2008. 
Expor as partes uniformemente na vida anímica do homem adulto, e sua importância se apóia no fato de que seus objetos são dados originária e imediatamente e podem ser verificados pela percepção interna. Porém, sua missão não se limita a conhecer o íntimo senão que ademais deve recolher e teorizar o aporte dos grandes conhecedores intuitivos e empíricos da alma, tal como se oferece na obra dos poetas e nas reflexões dos escritores. E finalmente deve servir de base para uma psicologia explicativa, criando uma terminologia justa, oferecendo análises seguras e facilitando um meio de controle para as teorias explicativas (DILTHEY, 1944, p. 50-51).

As ciências do espírito se apóiam por sobre os feitos espirituais dados pela vivência e, por extensão, sobre a realidade. Elas se produzem em um estado de percepção íntima que nasce quando dirigimos nossa atenção aos processos espirituais postos pelo pensar discursivo. Nesse estado de completo envolvimento entre espíritos alargam-se nossos conhecimentos do mundo interior, que se elevam ao nível da consciência, possibilitando-nos a autognose. O saber espiritual, viabilizado pela discursividade, está, neste sentido, fundado na relação possível entre a realidade passada e a realidade presente. Então, ao cientista do espírito cabe a função de apreciar o individual, descrever o singular, comparar as semelhanças e considerar as relações causais dirigidas à singularidade e que estão correlatas à história. Por esta via, ele inevitavelmente incidirá sobre os estados históricos de construção da cultura, portanto na gnoseologia, tão distante dos cientistas da natureza.

Além da Psicologia, Dilthey identifica a hermenêutica como fundadora das ciências do espírito. Por meio dela, o estudioso do espírito deve partir das manifestações sensíveis da vida, de suas objetivações e viver o processo de criação do mundo espiritual em seu processo histórico. Assim, defende, se está viabilizando o compreender (Verstehen) - processo mediante o qual conhecemos o psíquico através de signos sensíveis. Para Dilthey a compreensão permitiria interpretar as expressões e a hermenêutica asseguraria a validez geral dos resultados.

A função da hermenêutica, no contexto diltheyano, se constitui

Educ. e Filos., Uberlândia, v. 22, n. 44, p. 159-184, jul./dez. 2008. 
na tentativa de compreender a vivência por meio da classificação das expressões manifestas em conceitos, juízos e racionalização, objetivações da própria vivência na religião, arte, literatura, poesia, enfim, em todas as expressões do espírito objetivo. Por meio da hermenêutica o cientista do espírito descobre para cada grupo de expressões a correspondente espécie de compreensão, analisa suas formas elementares e determina suas categorias fundamentais. A psicologia está para as vivências, assim como a hermenêutica está para as categorias objetivadas das vivências.

Enfim, para Dilthey a consciência histórica, possibilitada pela sistematização da cultura e mediatizada pela psicologia e pela hermenêutica, mostraria a relatividade de toda construção, a relatividade do pensar humano e a relação incondicional entre o espírito e o tempo. Este modelo por ele traçado teria como mérito o desvelamento da concepção de universo, subjacente a todo e qualquer sistema. Pois, acreditava que nesta concepção se encontram as idéias, os valores e os princípios supremos que conduzem a vida. E a vida, diz ele, é o último posto de referência da filosofia.

No texto "Filosofia e enigma da vida", Dilthey diz que a função da filosofia consiste:

Em elevar à consciência e ao pensamento conceitual nosso ser em suas diversas manifestações da vida. Consiste em estabelecer a consciência da unidade em nossas experiências, em nosso fazer, em nossa vitalidade mesma, em elevar esta consciência ao pensamento conceitual (1954, p. 81).

Isto resulta na compreensão de que à filosofia cabe fundamentar e sistematizar o pensamento, originado nos domínios particulares da cultura, de modo a nos tornar cônscios das experiências de vida do passado e, assim, podermos exercer a crítica sobre o presente. Reflexão do espírito sobre si mesmo, como autognose, à filosofia cabe elevar à consciência os modos mesmos de atitude em sua relação com os conteúdos, investigando a experiência que surge neles e sua legitimidade. Pois, para Dilthey, 
a experiência da vida é a consciência e reflexão crescente sobre a vida.

Este processo de "mergulho" no mundo da cultura deve ser operado, diz Dilthey, de modo livre, tanto no campo da ciência, quanto da arte, da religião e da literatura para que os sistemas se constituam. Dessa forma, pensa Dilthey, a filosofia alcança a natureza do mundo e a própria vida que surgem, na verdade, da relação entre a cultura humana e seus complexos teleológicos. Porque a cultura, insiste, se nos organiza segundo as relações intrínsecas entre o conhecimento do mundo, a vida e as experiências do espírito e as ordens práticas em que se realizam os ideais de nossa conduta. Desse empenho, ou seja, dessa relação entre a filosofia com os distintos domínios da vida humana se processa, defende Dilthey, o direito da filosofia fundamentar e sistematizar não só o saber e as ciências particulares em que se tem consolidado o saber, mas também elaborar esses mesmos domínios em disciplinas especiais como: filosofia do direito, filosofia da religião, filosofia da arte e outras.

Ainda sobre o enigma da vida, Dilthey diz que ele:

Constitui o único, obscuro e espantável objeto de toda filosofia. Não o enigma do mundo, que constitui mas que uma metade objetiva desse obscuro novelo de problemas, sina, mas bem, o rosto da vida mesma, com seus olhos que miram o mundo ou o contemplam serena ou imaginativamente, com sua boca sorridente ou que se contrai em um trejeito de dor: a esfinge do corpo animal e rosto humano (1954, p.81).

O enigma da vida não são frias questões do intelecto, mas aspectos da vida que se apresentam em luta dentro do próprio coração. Foi em busca desse enigma que Dilthey se envolveu com a poesia, a arte e a literatura. Foi por meio dos olhos do poeta que ele tentou resgatar uma história não contada: a história da vida. Para ele, a alma do poeta se apresenta como fortemente catalizadora desse enigma. Ele diz que o enigma da vida se encontra na vitalidade personal de um homem que reage perante ela. Este homem, para Dilthey, aparece intratecido na arte, na poesia, na

Educ. e Filos., Uberlândia, v. 22, n. 44, p. 159-184, jul./dez. 2008. 
literatura que captam, com especial poder de desvelamento, os problemas da vida, através das metáforas, da parábola religiosa, enfim da linguagem figurada.

\section{Poesia e Literatura: a história da vida}

Segundo Amaral (1987), Dilthey é reconhecido como "o arguto historiador do espírito", face à destacada atuação no campo da literatura e da arte. É considerado pelos filósofos alemães contemporâneos, diz, como "o verdadeiro fundador da hermenêutica filosófica", uma vez que foi capaz de oferecer às ciências do espírito e à filosofia independência do domínio dos métodos das ciências da natureza, domínio esse proposto por defensores do positivismo e do cientificismo. Para Amaral, além de "arguto historiador do espírito", Dilthey foi um filósofo que tentou, por meio do conhecimento objetivo, apreender intuitivamente a verdade da vida e do mundo. Seu objetivo, afirma ela, era "descrever a vida" e penetrar no subterrâneo da estrutura histórica gigantesca para tentar enxergar "a vida como ela é" ou de "compreender a vida por si mesma".

Para Dilthey o poeta é um vidente da humanidade, portanto, sua produção se constitui em matéria prima fundamental para a compreensão dos conflitos, sentimentos e necessidades manifestas nas relações entre homens e grupos de homens. Por acreditar veementemente no poder da arte em traduzir a realidade, Dilthey, ávido por desvelar a trama do homem moderno, analisou, em duas obras, artistas que considerava exemplários da vida em seu tempo histórico: "Literatura e fantasia" e "Vida e poesia". Na primeira, analisou Shakespeare, Molière, Voltaire, Vittorio Alfieri, G. A. Bürger, Balzac, George Sand e Charles Dickens. Na segunda, Lessing, Goethe, Schiller, Jean Paul, Novalis, Federico Hölderlin. Os seus ensaios sobre a obra desses, conduziram-no a um particular processamento do método comparativo e trazer à tona os sentimentos humanos dados à vida. Os estilos eram importantes para Dilthey, as formas literárias também, mas mais importante era o que conseguia descobrir acerca do ideal de vida dos poetas 
que se entrelaçavam à totalidade moral de seu mundo e tempo a ponto de desmontar toda a construção imaginativa (Einbildungskraft) ${ }^{6}$ de uma época.

Profundo estudioso da poética ${ }^{7}$, Dilthey desenvolveu, com propriedade singular, o método comparativo. Mas para levar a cabo esta tentativa de comparação é preciso, adverte ele, partir de uma visão histórico-universal da literatura para apreender os limites e o caráter de cada uma das épocas poéticas. Seus conhecimentos, alerta, devem abarcar a cultura, as ciências, as artes e as filosofias da época de cujos poetas se ocupe. Tem também que saber servirse do instrumento da psicologia e da estética que a ele está vinculada. Para ele, os poetas e literatos ocupam um lugar de destaque na história do espírito. Por via deles, acreditava ser possível apreender a história e conhecer, por meio da consciência, o que pensavam, queriam e sentiam os homens em tempos e espaços diversos. Para isto, estudou tipos representativos na literatura e na poesia, abstraindo o enigma do mundo e da vida que a partir deles era possível depreender.

Historiador que via na literatura, na poesia e na arte condições fecundas de apreensão dos limites e propriedades das épocas, Dilthey tentou explicitar as inquietações do homem moderno. Considerados por ele como verdadeiros etnógrafos, os poetas e literatos foram seus cúmplices na descrição das vivências possibilitadas pela história. Mas, a historicidade - objeto de conhecimento de Dilthey - está na vida psíquica que, para ele, se manifesta em todo sistema cultural produzido pela humanidade. Os espíritos aos quais recorreu eram-lhe a fonte de historiografia, a força catalizadora dos enigmas da vida. Para ele, o renascimento ignorou o poder da poesia e da literatura em revelar a verdadeira natureza da vida. Na prática, comprova que a literatura e a poesia

6 Nos adverte sempre o tradutor - Eugênio Imaz - que imaginação é uma palavra que Dilthey emprega, indistintamente, com o mesmo sentido de fantasia.

7 Designa Dilthey como poética toda obra que expressa a vivência, a vida, e que nos fala através das palavras, das cores, das linhas, das formas plásticas e dos acordes.

Educ. e Filos., Uberlândia, v. 22, n. 44, p. 159-184, jul./dez. 2008. 
têm um lugar importante na consciência e, portanto, muito a dizer sobre o mundo e seus personagens.

As imagens poéticas são, para Dilthey, verdadeiras expressões do mundo e da vida anímica, portanto, material legítimo de compreensão da realidade. Pelas imagens poéticas, interroga o mundo e crê que elas são sua primeira representação histórica e exclama: "quão pobre seria nosso conhecimento psicológico sobre os sentimentos sem os grandes poetas que têm expressado toda a diversidade de afetos e com freqüência têm feito ressaltar de maneira surpreendente as relações estruturais no universo dos sentimentos!" (DILTHEY, 1944, p. 57). Para ele, a imaginação do poeta é um conhecimento abundantemente psicológico porque se refere à vida sentimental, à vivência e à conexão psíquica entre o mundo e a pessoa.

Para Dilthey, todas as criações humanas surgem da vida psíquica e de suas relações com o mundo exterior. No caso da poesia e da literatura, a criação se torna mais próxima do mundo volitivo e das representações mais primárias dos sentimentos humanos. Para ele, a poesia é elemento, por excelência, de compreensão da vida; nela reinam livremente os domínios da realidade e das idéias, pois tem na linguagem (no discurso) o instrumento expressivo para tudo quanto pode presentear-se a alma do homem - objetos exteriores, estados íntimos, valores e determinações da vontade. E, o que é mais importante, a versão particular do espírito do poeta que, para Dilthey (1944, p. 175), "é um homem verdadeiro que se abandona livremente ao influxo da vida".

Como o religioso, o filósofo e o artista, o poeta, diz Dilthey, se distingue do homem corrente e até mesmo de gênios de outro gênero porque guarda semelhantes momentos da vida na lembrança, eleva seu conteúdo à consciência e liga as experiências singulares a uma experiência geral de vida. Com isto cumpre uma função importante não só para si, mas também para a sociedade, pois retira do homem o enigma do mundo e da vida e a ele o devolve. O poeta é o verdadeiro homem porque se abandona à ação livre da vida. No homem corrente a reflexão sobre a vida é demasiado débil para poder levar, na moderna anarquia das 
concepções do mundo, uma posição firme; já no poeta a ação dos aspectos diversos da vida é demasiado forte, sua sensibilidade é demasiado grande para que possa satisfazer um tipo perfilado de concepção do mundo como aquele que corresponderia ao que a vida lhe disse em cada momento. Ele também se distingue:

Pela intensidade e precisão das imagens perceptivas, a riqueza das mesmas e o interesse que as acompanha; pela claridade do desenho, a força sensível e a energia da projeção próprias de suas imagens e das figuras que surgem delas; pela força com que reproduz estados anímicos, experimentados por ele, captados em outros, em conseqüência, acontecimentos e caracteres inteiros que se dão no enlace de em tais estados; pela enérgica animação das imagens, e a satisfação que assim se origina, na intuição empregada de sentimentos; finalmente se distinguem pelo fato de que nele as imagens e combinações se despregam livremente por cima das fronteiras do real. Cria situações, figuras e destinos que excedem a realidade (DILTHEY, 1945, p. 37-43).

Na poesia, assegura Dilthey, contém sempre uma concepção de realidade que resulta da relação interna do poeta na experiência da vida com a imagem do mundo, uma relação da qual pode derivar-se sempre um ideal de vida.

Ao realizar seus estudos, Dithey acaba por mostrar que a poesia tende a ocupar um lugar cada vez mais autônomo na ciência moderna e que isto se deve, fundamentalmente, porque o poeta, como vidente, tem muito a dizer sobre a verdadeira natureza da vida na idade moderna. Este poder resulta em uma relação histórica da poesia com a filosofia. A visão poética da vida articulou, indelevelmente, poetas e filósofos a ponto de um não poder dar um passo sem o outro. Não obstante, ele diz que a poesia atua sobre o pensamento filosófico. Para demonstrar sua assertiva, resgata Homero e diz que sua intuição sobre os homens serviu de material de análises psicológicas e que sua visão da vida e sua concepção de mundo foram objeto de reflexão de grandes filósofos; cita ainda a alegria dos artistas do Renascimento pela vida que se

Educ. e Filos., Uberlândia, v. 22, n. 44, p. 159-184, jul./dez. 2008. 
converteu, na filosofia de Bruno, na doutrina da imanência dos valores no mundo; relembra o Fausto de Goethe, que influiu na direção da filosofia sobre a potenciação da existência humana; ressalta os dramas históricos de Schiller, que exerceram uma forte influência no desenvolvimento da consciência histórica; lembra o panteísmo poético de Goethe, que preparou o panteísmo filosófico. Em sentido inverso, acresce que a filosofia também exerce sua influência sobre a própria poesia, principalmente no que se refere à elaboração de uma visão de vida e tipos cerrados de visão de mundo. Assegura ele: Eurípides estudava os sofistas; Dante os pensadores medievais e Aristóteles; Racine procede de Port-Royal; Diderot e Lessing, a filosofia da ilustração; Goethe mergulha em Spinoza e Schiller e se converte em discípulo de Kant. E, completa: se Shakespeare, Cervantes e Molière não se entregaram a nenhuma filosofia, suas obras estão penetradas por infinitas e finas influências de doutrinas filosóficas para descobrir os aspectos da vida.

Para Dilthey, enganam-se os que pensam que os poetas e literatos se deleitam simplesmente com as imagens. Eles, afirma, expressam por meio das imagens compreensões do mundo e que através do estudo individual dos grandes poetas se estaria volvendo a história universal da poesia e da literatura e resgatando determinadas propriedades fundamentais do espírito, seus grandes traços, sua estrutura, enfim, a própria constituição da vida anímica. Em verdade, para Dilthey a arte é a primeira representação do mundo histórico-humano. Por acreditar nisso, em "Literatura e Fantasia", livro que registra a história moderna, Dilthey reconstitui a vida dessa época por intermédio dos grandes expoentes do teatro, da poesia e da literatura e diz que

A arte e a poesia dos povos europeus modernos se encontra na fronteira entre a evolução medieval e moderna destas nações com uma grande elevação da arte e da poesia que a tudo domina e resume e para a qual levanta seu assombrado olhar ao homem atual, formado nas disciplinas científicas (1963, p.13).

A partir dos grandes poetas das monarquias nacionais (Itália, Países Baixos, Alemanha, Espanha, Inglaterra e França), Dilthey 
constata um traço dominante: que estes penetram na consciência do poder, embebida de respeito e veneração pela monarquia, que encarna naquela época a soberania e a força do Estado. Desta íntima relação dos poetas com a sociedade aristocráticomonárquica, ele diz surgir uma amorosa imersão no mundo humano circundante e expor criativamente os homens desta época nas formas mais elevadas da poesia, do drama e da novela. Artesanato básico da poesia, os tipos humanos mais comuns eram exibidos pela descrição de seus comportamentos e sentimentos. As atitudes mais comuns são colocadas com precisão em animadas figuras humanas e os estilos tomam formas bem definidas e acabam por desvelar o próprio espírito do poeta. Assim, Dilthey penetra nas representações primárias dos sentimentos dos poetas, arrancando deles a história da vida daquela época. Ele diz que a plasticidade da poesia e da literatura expõe infinitos matizes da guerra e do amor dando expressão a um tema fundamental em variações sempre novas: o direito do forte, o encanto e a astúcia das mulheres, as incalculáveis e loucas decisões amorosas.

Esta cultura se mostra aos olhos de Dilthey como visivelmente articulada à vida nacional, com seus nobres, heróis e personalidades bizarras. A fantasia ergue, segundo ele, uma energia que ultrapassa toda a realidade, como são os dramas de Corneille, as novelas de Rabelais, as tragédias de Shakespeare. Os grandes temas se localizavam na sociedade nobre e a linguagem e os gestos se ajustavam aos costumes da corte. Na captação dessa vida, o poeta (re)elabora as palavras, (re)produz o cenário e faz da fantasia uma força de expressão do movimento vivo e garante uma conexão direta com a vida anímica. As personagens expõem os homens em sua própria estrutura. A epopéia heróica, diz ele, revela com particular propriedade o sentimento de poder que nesta época animava as monarquias aristocráticas, as guerras e aventuras no Novo Mundo. Como exemplo, nos traz Os Lusíadas de Camões que contém tudo o que a época era capaz de brindar: o orgulhoso sentimento de poder nacional, a vida aventureira, o hálito do mar, o aroma e o brilho meridional das Índias.

Assim, adverte Dilthey, até a concepção do mundo na época

Educ. e Filos., Uberlândia, v. 22, n. 44, p. 159-184, jul./dez. 2008. 
conduz os grandes poetas e artistas ao desenvolvimento de sua arte de modo a fotografar a estrutura mesma do indivíduo, pois as condições possibilitavam tal situação. O cenário, neste caso, favoreceu a produção de uma literatura de conhecimento do homem e uma teoria da direção da vida que expunha temperamentos, caracteres e qualidades humanas; não chegou a se conformar em psicologia como hoje entendemos, mas, sem dúvida, seu conteúdo se dirigia à questão da natureza humana e às formas de existência individual que distinguiam os homens entre si. Esta poesia e literatura se ofereciam em escritos pedagógicos e, também, em forma de conversações, cartas e ensaios. Desta maneira se comunicava a todo o mundo culto a nova arte de ver o homem, que se difundiu em todos os países e não chegou a ser concebida como ciência especializada, mas por muitos serviu como estudo da alma, chave para o conhecimento e conduta da vida. Tenta-se, com esta produção, que tão fortemente falava do enigma da vida, apreender os fundamentos fisiológicos da vida da alma. As paixões são expostas como forças que mantêm em jogo o processo vital da alma, portanto úteis e valiosas à expressão da vida anímica manifesta nos rostos, nos olhares, nos gestos, nas linguagens, e que os autores tão minuciosamente escreviam e serviam de instrumental para auxiliar os que precisavam calcular a vida.

Como se pode constatar a intenção que anima Dilthey a desenvolver estudos sobre a poesia, a literatura e a arte está em credenciá-las como potencialmente capazes de nos fazer compreender o espírito humano e demarcar o seu lugar histórico. As obras dos poetas são para ele a expressão da alma e, portanto, a manifestação da história da vida como ela é, por isso ressalta a significação capital da poesia e da literatura para a filosofia e leva, às últimas conseqüências, como nos diz Eugênio Imaz, este obsessivo desejo alemão - unir o conhecimento poético ao filosófico. Nessa tentativa apaixonada, Dilthey escreveu uma história que pretendia distanciar-se de qualquer idealismo. Com sua incessante análise da vivência, contrapôs-se à psicologia explicativa e, por caminhos rigorosos, tentou dar voz a uma psicologia real, pautada em uma densa descrição histórica do homem.

Educ. e Filos., Uberlândia, v. 22, n. 44, p. 159-184, jul./dez. 2008 
Dilthey cria que no terreno da poética poderia estruturar uma ciência particular do espírito. Absolutamente envolvido com as questões teóricas de seu tempo, tem consciência de que a conjuntura histórica clamava pela fundação de uma ciência empírica dos fenômenos do espírito. Partiu, então, para a busca de resolução a tal questão com a idéia de que cada sistema cultural apresenta uma estrutura e que poderia estar ocupado em identificar como operar cientificamente o caminho capaz de alcançar esta estrutura e, assim, estabelecer um meio particular de estudar o espírito. O caminho que percorreu o fez identificar duas grandes possibilidades de trabalho: a psicologia descritiva e a hermenêutica, ambas necessariamente ligadas a questão da vida. Uma vida já compreendida porque passada pelo crivo do espírito do poeta, do artista, do literato. Trata-se, portanto, da análise de uma vivência compreendida e, neste caso, de uma compreensão da compreensão, de uma vivência já construída como saber.

A vivência é para Dilthey uma realidade direta, no sentido de que potencialmente lança bases à relação do homem com o mundo. Ela é a experiência no seu estado puro; a conexão entre o espírito e o tempo, portanto, realidade histórica; mundo exterior; saber estruturado pela compreensão da vida. Espírito e mundo encontramse articulados na vivência expressada, portanto ela se põe como material privilegiado de descrição psicológica e de hermenêutica das manifestações da vida - fundamentos das ciências do espírito. Mas, alerta o autor, para alcançar esta estrutura é preciso dar conta dos nexos efetivos que das vivências emanam, isto é, uma teleologia, um sentido que decorre da própria vivência ao processar relações interhumanas e, dessa forma, revelar o mundo histórico. O nexo efetivo, produto das interações individuais, participa dos mesmos caracteres que acusa a teleologia imanente da vida individual. Como esta, podem-se, também, estudar os nexos efetivos fundamentais, os sistemas culturais - nexos finais -, as organizações e outros nexos não menos efetivos: os movimentos históricos, as épocas, as nações. O mundo histórico, conclui, é assim estruturado: fundado na vivência e estruturado pelas ciências do espírito em uma aproximação típica incessante até chegar a captar o indivíduo em sua efetividade.

Educ. e Filos., Uberlândia, v. 22, n. 44, p. 159-184, jul./dez. 2008. 
Por esta via, Dilthey ergue sua teoria estrutural que estabelece o fundamento primeiro das ciências do espírito; parte da estrutura psíquica, da vivência e da estrutura especial da vivência do saber e do compreender. Um saber que abarca saberes de objetos, de valores e de fins ${ }^{8}$ e que são expressos em juízos, nas exclamações e nos imperativos. Enfim, Dilthey ambicionava, mediante a poesia, a literatura e a arte, explicar com exatidão a ação dos processos psicológicos nos produtos históricos.

\section{Considerações finais}

Dilthey foi, na verdade, um estudioso pouco analisado, segundo os raros resenhistas e tradutores de suas idéias. Para alguns isto se explica devido a um certo grau de fragmentação no conjunto de sua obra. Apesar disso, visualiza-se, ao "tomá-lo" em seu trajeto, uma evidente interligação entre seus escritos, operandose uma magnífica e impressionante união de idéias, o que, de certa forma, acaba por dificultar o caminho daqueles que, como eu, tentam, não raramente, esquematizar o pensamento de outrem e buscar nele uma certa linearidade evolutiva. O próprio Haidegger adverte, em 1927, que para entender Dilthey, para chegar ao

8 Esclarece o autor que o saber de objetos é um saber acerca da realidade, seus enunciados são juízos que predicam a realidade. Abarcam também valores e fins, pois na realidade da vida se dão todas estas classes de fenômenos. O saber de valores e de fins estuda a conexão especial que se estabelece dentro da atitude afetiva e da atitude volitiva, com independência do predicado de existência; relações de valores entre si, dos fins entre si e com a conexão vivencial respectiva. $\mathrm{O}$ conhecimento dos valores antecede o dos fins e o determina, como o conhecimento da realidade precede a ordem dos valores.

9 Não encontrei nenhum ensaio de Dilthey traduzido para a língua portuguesa, talvez isto explique, de alguma maneira, sua significativa (para não dizer total) ausência nos escritos filosóficos brasileiros. Para Eugênio Imaz, Dilthey permaneceu ignorado talvez pela falta de uma expressão particular, a indiferença pelo uso de uma terminologia técnica pessoal e pela despreocupação por escolher ou cunhar expressões novas. Diz ainda que a originalidade de seu pensamento se faz por expressões imprecisas, aptas a fornecer o equívoco.

Educ. e Filos., Uberlândia, v. 22, n. 44, p. 159-184, jul./dez. 2008 
subterrâneo de suas idéias, é preciso trato assíduo e familiaridade com todos os seus escritos.

Completamente em sintonia com o seu tempo, Dilthey dedicou sua vida ao estudo da Religião, da Arte (Poesia e Literatura, em especial) e da Filosofia para entender o homem e o mundo, pois para ele os conteúdos religiosos, poéticos e filosóficos são necessários para a compreensão da relação entre ambos (homem e mundo) em seu movimento. Ao contrário de Hegel, visualizou nestes conteúdos uma relatividade histórica que se contrapunha ao absolutismo enxergado por Hegel, para quem estes conteúdos eram verdadeiras manifestações do espírito absoluto. Levadas às últimas conseqüências, as interpretações de Dilthey concluem que estes espíritos não são absolutos, mas objetivos, porque não têm, assegura, ao alcance da consciência humana, nenhum espírito absoluto: todo espírito é relativo. Obstinado em comprovar a veracidade de sua idéia anti-hegeliana, Dilthey realiza inúmeros ensaios que demonstram variedades incontestes em sucessivos sistemas que assinalam sua relatividade ao estarem afeitos às condições históricas.

Acerca da filosofia, foi enfático em defender sua função de autognose (Selbstbessinung), ou seja, de estudo das condições do conhecimento na consciência, ressaltando as possibilidades históricas de apreensão do mundo. Ao desenvolver esta idéia, combate a crítica da razão pura de Kant que, segundo ele, colocou no lugar da metafísica dogmática a metafísica crítica quando assinala o emprego transcendente de suas categoria - o a priori. Desta feita, oferece as bases para a formação das ciências sistemáticas do espírito no estudo da vida histórica e institui a questão da conexão como procedimento metodológico, necessário ao processo de sistematização das ciências. O problema da conexão é, inclusive, experimentado por Dilthey no estudo das ciências morais e políticas e passa a ser a "chave" de sua história. Em última instância, consegue, então, com sua visão metódica colocar a consciência empírica no lugar do idealismo alemão.

Dando expansão a essas posições teóricas, Dilthey elabora "Psicologia e Teoria do Conhecimento" e constitui uma teoria da

Educ. e Filos., Uberlândia, v. 22, n. 44, p. 159-184, jul./dez. 2008.

180 
estrutura que dá origem a uma teoria do saber. Com uma habilidade intelectiva singular, propõe uma Psicologia descritiva e analítica que acaba por dar suporte às ciências do espírito. Nesta Psicologia entende que as representações não são fixas, mas que estão em conexão com a real vida psíquica que se encontra impregnada de sentimentos, interesses e vontade.

Por esta via fecunda, Dilthey desnaturaliza o espírito ao tempo em que estabelece as bases gnoseológicas autônomas das ciências do espírito. Sua teoria da estrutura busca, nas concepções do mundo subjacente ao espírito, uma questão nada natural e que garante a conexão lógica que circunda a consciência em sua possibilidade histórica: o enigma. Para Dilthey o mundo se dá, totalmente, como enigma. É este enigma que desafia o homem por séculos e séculos; é ele a esfinge da vida e está contido no sorriso dos lábios e na profunda melancolia do olhar.

O homem, identifica Dilthey, é um sujeito de atitude contemplativa, volitiva e afetiva. São estas atitudes o material pelo qual é possível conhecê-lo e que devem ser descritas e analisadas pela Psicologia. Elas estão sempre vivas na história humana, portanto, na cultura. $\mathrm{O}$ homem, diz ele, conhece a realidade pela inteligência, a valoriza em sentimentos e a ajusta pela vontade, isto conforma a sua unidade psíquica em articulação com a concepção de mundo por ele elaborado nas expressões da inteligência. Assim é sua vida. Então, se quisermos conhecer este homem temos necessariamente que recorrer às suas elaborações filosófica, religiosa e artística. Através da filosofia conhecemos o valor universal do conhecimento do mundo; através da religião, as relações volitivas com a força suprema; através da poesia, a ordem sentimental dos valores da vida. Mas o enigma, adverte, é inacessível, apesar de o homem procurá-la, nestes âmbitos, incansavelmente. Assim, o problema do enigma nunca será resolvido e será sempre buscado, mas, retruca, deve ser buscado na vida mesma.

Sobre a poesia, cabe aqui trazer mais algumas idéias que ratificam as já ditas, mas que só nos farão entender ainda mais Dilthey. Ele dizia que a base de toda a verdadeira poesia é a

Educ. e Filos., Uberlândia, v. 22, n. 44, p. 159-184, jul./dez. 2008 
vivência, a experiência viva, elementos psíquicos de todo gênero que se mantêm em relação com ela; que todas as imagens do mundo exterior podem convergir, indiretamente, através dessa relação, em material para a criação do poeta. As representações são o solo de onde a poesia recolhe a parte essencial de seu alimento; os seus elementos, motivo, fábula características e ação não são mais do que transformações de representações da vida. Os nexos de processos que oferecem as experiências da vida fazem mais do que sofrer uma transformação para se converterem em estética. Não existe nenhuma moral de teatro, nenhum desenlace que satisfaça na novela e não na vida; isto é o que nos prende em um grande poema, o fato de que surge de uma alma parecida com a nossa, só que mais viva, e desta forma encanta nosso coração sem tirá-lo de seus laços nem colocá-lo na atmosfera escassa de um mundo estranho a nós. As realizações da imaginação não se operam em um espaço vazio; tem que brotar de uma alma sã, saturada de realidade, poderosa, e deste modo temperar e reforçar o melhor do ouvinte e do leitor e ensinar-lhe a compreender melhor seu próprio coração, a observar os degraus escondidos e uniformes de sua vida e, ao mesmo tempo, fazer frente ao extraordinário.

As idéias contidas nestes enunciados de Dilthey indicam que em toda poesia germina uma faticidade histórica; que elas revelam um modo determinado de ver os homens, tipos característicos e que, portanto, são material indispensável, privilegiado, de compreensão do espírito. Neste sentido, na criação poética "descansa sempre a energia do viver" e o poeta, em toda a sua intuição externa,

[...] opera um temperamento vivo que acumula e configura a intuição; possui e goza de sua própria existência em um sentimento forte de vida, nas oscilações entre a alegria e a dor projetadas sobre o fundo claro e puro da situação das imagens da existência (DILTHEY, 1945, p. 34).

Isto significa que a fantasia criadora do poeta se nos apresenta como um fenômeno que sobrepassa por inteiro a vida cotidiana

Educ. e Filos., Uberlândia, v. 22, n. 44, p. 159-184, jul./dez. 2008. 
dele e dos homens de seu tempo, por isso tem como função conservar, fortalecer e despertar em nós essa vida vivida, a energia do sentimento da vida que nos leva aos mais belos momentos, a esta interioridade de olhar com a qual desfrutamos do mundo. Esta função, vai defender Dilthey, está condicionada por uma superior energia de certos processos psíquicos. Assim, quando nos debruçamos sobre a produção poética estamos adentrando neste universo psíquico e trazendo à baila um quadro profundo e verdadeiro sobre o modo particular de viver e poetizar dos poetas.

Enfim, é difícil não reconhecer o talento intelectivo de Dilthey, ignorar a beleza de sua alma, a vontade de seu espírito e a plasticidade de suas idéias. É um poeta, sem dúvida é um poeta. Suas construções intelectuais são, já disse Imaz, um retoque constante das formas plásticas de suas construções intelectuais a buscar constantemente na vida e na história novos materiais de trabalho.

\section{Referências}

AMARAL, Maria Nazaré de Camargo Pacheco. Dilthey: um conceito de vida e uma pedagogia. São Paulo: Perspectiva, 1987.

DILTHEY, Wilhelm. La esencia da la filosofia. Tradução Eugênio Pucciarelli. Buenos Aires: Editorial Losada, 1944.

Vida y poesia. Tradução Eugênio Imaz. México: Fondo de Cultura Económica, 1945.

Introducción a las ciencias del espíritu. Tradução Eugênio Imaz. México: Fondo de Cultura Económica, 1949.

Teoria de la concepcion del mundo. Tradução Eugênio Imaz. México: Fondo de Cultura Económica, 1954.

Literatura y fantasia. Tradução Emílio Uranga e Carlos Gerhard. México: Fondo de Cultura Económica, 1963. 
IMAZ, Eugênio. El pensamiento de Dilthey: evolución y sistema. México: Fondo de Cultura Económica, 1946.

Data de Registro: 03/05/06

Data de Aceite: 11/09/07

Educ. e Filos., Uberlândia, v. 22, n. 44, p. 159-184, jul./dez. 2008.

184 